\title{
A time series based prediction model for urban development plans using an Artificial Neural Network: Koya in 2020
}

\author{
S. M. Abdullah \\ Department of Software Engineering, Koya University, Kurdistan, Iraq
}

\begin{abstract}
Urban development plans always designed based on two important factors; population growth and city's expansion. In many cases, the size of expansion of a city depends on the rate of population growth. The expansion process for a city may include many types of projects, such as building new residential and commercial areas, opening internal and access roads, constructing new service buildings (schools, hospitals, etc.) with providing many types of services such as electricity power, communication access points and towers, and sewerage with water net systems. In this project, an accurate prediction model with prediction function is proposed. The model depends on a time series based Artificial Neural Network to achieve the work. The input data for this model will be the number of families, number of students, and number of registered cars to get fuel in Koya petrol stations. These records that are distributed over different spans of years (from 2000 to 2013) were collected in Koya city. This work has general and specific aims. The specific aim of this work is to support some governmental service departments in Koya through providing a correct prediction about the size of requirements for this city in 2020. This case could be generalized to other cities similar to Koya, which is the general aim of this work.
\end{abstract}

\section{Introduction}

Due to improving the income of people in Koya city, the expansion of this city has been growing rapidly since 2003. There are many new quarters and residential areas have been settled, many new access and internal roads have been constructed, and many schools and hospitals have been built. Moreover, the area witnessed establishing a new university (Koya University). This 
expansion started immediately after 2003, when Iraq in general and Kurdistan Region more specifically have been liberated from a strong control of a peremptory regime. Such expansions should be achieved with a very strong plans and preparations, however, there wasn't any plan for cities and there were no drawings and designs for the city's future. Moreover, there was nothing called master plan for this area. This situation wasn't only covered Koya city; however, it covered all Iraq's cities. The mentioned expansion was processed without any plan, and many mistakes followed the achievement process. Therefore, this work proposes a prediction model to obtain some figures about this area, and based on, correct plans can be designed.

This work proposes an Artificial Neural Network (ANN), as a prediction model [1], to simulate the past data of Koya city and predict some figures about the future expansion of this area. This work depended on Time Series data; therefore it employed the time series ANN. Such structure of ANN has been employed many times as forecasting models for climate prediction, economic estimation, disease analysis, and energy consumption computing [2, 3]. Data for this work has been collected in three different areas; family numbers, student numbers, and number of cars that their owners are live in Koya. Simulation on each datasets has been done individually. Each simulation gives a specific regression equation, and this work tested them individually. Results showed that the average performance of this model is 0.0635 . The average growth in this city is $65.11 \%$.

\section{Urban development prediction model}

\subsection{Data collection}

To check the way that a city might be expanded, figures from different fields can be analyzed. A dataset from education, number of houses, number of families, number of vehicles, and number of patients can be used to answer how a city is expanding? In this work three types of dataset are involved; number of students, the number of families and the number of cars that stayed inside Koya for 24 hours, seven days a week. Because the prediction model of this work is the time depended model, the timeline of collected data is also considered. Table 1 shows figures of data collected from three different fields.

\subsection{Time series based ANN}

In this work, there is a time series type of problem. Therefore, the type of Neural Network (NN) that proposed by this work is a time series based NN. Figure 1 shows the structure of the proposed network, and the output prediction of this model is shown in equation (1) [4]. This work uses Matlab simulation to build the proposed prediction model [5].

$$
y(t)=f(y(t-1), \ldots \ldots y(t-x), i(t-1), \ldots . i(t-x)
$$

where $y(t)$ is the output at time $t, i(t)$ is the target at $t, x$ is the size that set feedback delay size. 
First International Symposium on Urban Development: Koya as a Case Study 259

Table 1: $\quad$ Records used as input for the time series based Neural Network.

\begin{tabular}{|c|c|c|c|}
\hline Year & No. of students & No. of families & No. of cars \\
\hline 2000 & 12743 & 9553 & 691 \\
\hline 2001 & 13630 & 10471 & 705 \\
\hline 2002 & 13980 & 10853 & 753 \\
\hline 2003 & 14020 & 11560 & 1134 \\
\hline 2004 & 14178 & 11889 & 1328 \\
\hline 2005 & 14638 & 12204 & 1324 \\
\hline 2006 & 14994 & 13074 & 1449 \\
\hline 2007 & 15169 & 14077 & 1599 \\
\hline 2008 & 15543 & 15367 & 1682 \\
\hline 2009 & 16050 & 15945 & 1752 \\
\hline 2010 & 16620 & 16501 & 1818 \\
\hline 2011 & 16813 & 17032 & 1905 \\
\hline 2012 & 17162 & 17725 & 2005 \\
\hline 2013 & 17566 & 18529 & 2106 \\
\hline Collected from: & $\begin{array}{l}\text { General } \\
\text { Directorate of } \\
\text { Education in } \\
\text { Koya }\end{array}$ & $\begin{array}{l}\text { Center of food } \\
\text { distribution in } \\
\text { Koya }\end{array}$ & $\begin{array}{l}\text { Center of fuel } \\
\text { coupon } \\
\text { distribution in } \\
\text { Koya }\end{array}$ \\
\hline
\end{tabular}

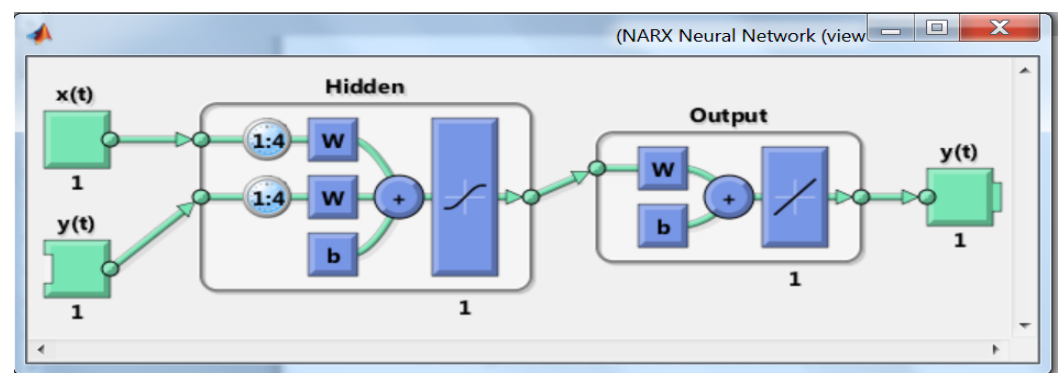

Figure 1: $\quad$ The structure of a time series based neural network. 


\subsection{Training phase}

To teach the proposed model, this work has clamped each dataset to ANN individually. At each training cycle, the proposed ANN will learn how the way of expansion of an event (number of families increasing, student's number increasing, and the car's number increasing) is going on. Figures 2 below show the training performance of each dataset individually.

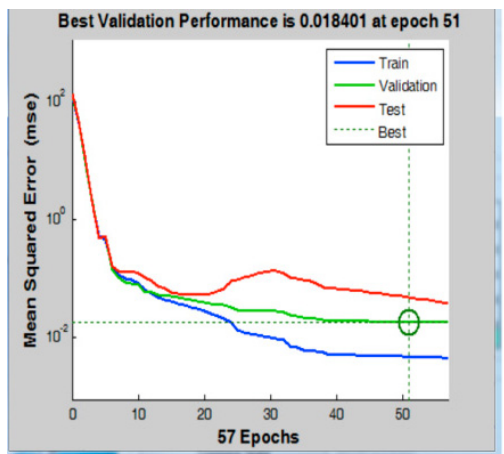

(a)

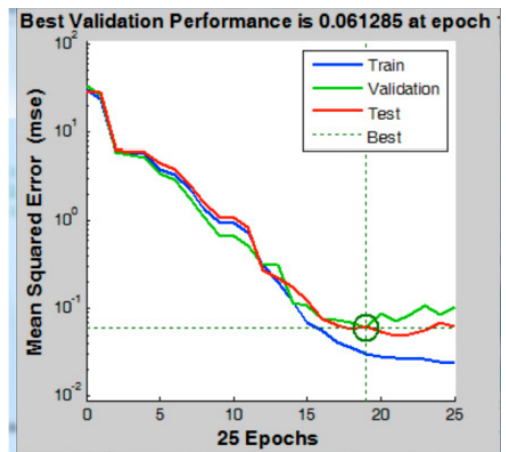

(b)

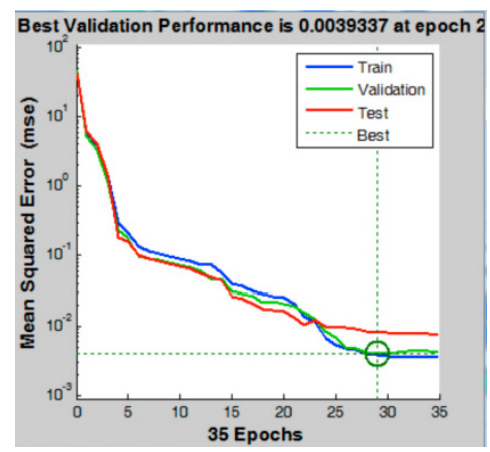

(c)

Figure 2: $\quad$ Training phases of proposed ANN on three dataset types.

(a) Training on family numbers; (b) Training on student numbers;

(c) Training on car numbers.

\subsection{Testing phase}

To test the ANN model, this work has partitioned each dataset into two groups; the first group is used for training phase, which covers $75 \%$ of the whole data. The second group, which covers $25 \%$ of whole data, is used for testing. Data in the second group has not involved within the training phase. Therefore, they can be considered as unseen data. The performance indicator has been computed for each testing phase. The calculation of performance indicator depends on Equation (2) [6]. 
First International Symposium on Urban Development: Koya as a Case Study 261

$$
\text { Output }=\frac{1}{n} \sum_{i=1}^{n}\left(\hat{y}_{i}-y_{i}\right)^{2}
$$

where $\hat{y}$ is the predicted value and $y$ is actual value at time $i$. Table 2 shows the performance indicator for each testing phase.

Table 2: $\quad$ Performance indicators for time based Neural Network prediction model.

\begin{tabular}{|c|c|c|c|}
\hline Performance indicator & $\begin{array}{c}\text { Family } \\
\text { numbers }\end{array}$ & $\begin{array}{c}\text { Student } \\
\text { numbers }\end{array}$ & $\begin{array}{c}\text { Car } \\
\text { numbers }\end{array}$ \\
\hline $\begin{array}{c}\text { Mean squared normalized error } \\
\text { performance function }\end{array}$ & 0.0146 & 0.0812 & 0.0947 \\
\hline
\end{tabular}

\section{Predicted rate for events}

As indicated in Table 1, the performance indicator for the ANN model is good enough for making prediction for each event that mentioned in section 2.3. The input value for each training phase is 2020, which is the time when this work attempted to find the prediction rate for three events. Table 3 shows these rates.

Table 3: $\quad$ The prediction figures for 2020.

\begin{tabular}{|c|c|c|c|}
\hline Year & $\begin{array}{c}\text { Predicted number } \\
\text { of families in } \\
\text { Koya }\end{array}$ & $\begin{array}{c}\text { Predicted number } \\
\text { of students in } \\
\text { Koya }\end{array}$ & $\begin{array}{c}\text { Predicted number } \\
\text { of cars at Koya }\end{array}$ \\
\hline 2000 & 10441 & 12743 & 690 \\
\hline 2010 & 16994 & 16610 & 1754 \\
\hline $\begin{array}{c}\text { (Predicted) } \\
2020\end{array}$ & 25682 & 20978 & 2913 \\
\hline
\end{tabular}

\section{Conclusions}

To cover city's expansion, it is very necessary to estimate how the population is growing. Accordingly, many population dependent parameters can be analyzed then estimation can be obtained for a few years in advance. This study showed some figures about Koya city through three different parameters. The first parameter is family number, which has been estimated that average increase for every 10 years is $56.9 \%$. The second parameter is student number. The average 
increase is $28.45 \%$, while the average increase of car's number for every ten years is $110 \%$. From these three figures we can conclude the following points:

1. The number of family members is more than four, because the percentage of increasing the family numbers is passed $50 \%$. This point can be bring the attention of Koya municipality, Koya Center for Food Distribution, Power Distribution Department in Koya, Post Office and Communication Department in Koya, and Health Care with Hospitals in Koya.

2. Growth of student's number is changed very stably. An education department in Koya can proceed with their plan, if they have, to keep their capability of registering new students. They should keep in their mind that every year around 700 new students are expected for registration.

3. Private transportation becomes more popular that public one. This pushes Traffic Department in Koya to work harder to provide parking, traffic jam arrangement, and more licenses are expected.

\section{References}

[1] Taylor, J.W. and R. Buizza, Neural network load forecasting with weather ensemble predictions. Power Systems, IEEE Transactions on, 2002, 17(3): pp. 626-632.

[2] Zhang, G., B. Eddy Patuwo, and M. Y Hu, Forecasting with artificial neural networks: The state of the art. International journal of forecasting, 1998, 14(1): pp. 35-62.

[3] Kalogirou, S.A., Applications of artif cial neural-networks for Energy Systems: Adaptive Complexity, 2013: p. 17.

[4] Vlahogianni, E.I. and M.G. Karlaftis. Testing and Comparing Neural Network and Statistical Approaches for Predicting Transportation Time Series. in Transportation Research Board 92nd Annual Meeting. 2013.

[5] Palm, W.J., Introduction to MATLAB 7 for Engineers. Vol. 1. 2005: McGraw-Hill, New York.

[6] Bird, S.M., et al., Performance indicators: good, bad, and ugly. Journal of the Royal Statistical Society: Series A (Statistics in Society), 2005, 168(1): pp. 1-27. 